\title{
Secondary cancer in a survivor of Hodgkin's lymphoma: A case report and review of the literature
}

\author{
MAJA LISIK-HABIB, URSZULA CZERNEK, SYLWIA DĘBSKA-SZMICH, MAGDALENA KRAKOWSKA, \\ JOANNA KUBICKA-WOŁKOWSKA and PIOTR POTEMSKI
}

Department of Chemotherapy, Medical University of Lodz, Copernicus Memorial Hospital, Lodz 93-513, Poland

Received April 17, 2014; Accepted October 31, 2014

DOI: $10.3892 / 01.2014 .2799$

\begin{abstract}
Hodgkin's lymphoma (HL) is one of the most curable malignant diseases in adults. However, HL patients have a higher risk of developing second malignancies compared with the general population. The population of adult cancer survivors is growing, thus, the long-term effects of cancer treatment, including secondary cancer development, have become an increasingly important concern in the field of oncology. The current study presents the case of a female HL survivor who developed two secondary malignancies within 29 years of follow-up. Furthermore, a review of the literature was conducted, which focused on secondary breast and gastrointestinal cancers in HL survivors.
\end{abstract}

\section{Introduction}

Hodgkin's lymphoma (HL), which predominantly occurs in young and middle-aged individuals, is one of the most curable malignant diseases in adults. Modern treatments have increased the number of malignant disease survivors, for example therapeutic advances over the past few decades have resulted in a significant improvement in the HL five-year survival rate $(1,2)$. However, cancer survivors are at risk of developing secondary malignancies. Thus, late complications of cancer therapy, including secondary cancer development, are now an important area of concern. The current study presents the case of an HL survivor who was treated for HL in 1985 and developed two secondary malignancies within 29 years of follow-up. Written informed consent was obtained from the patient.

Correspondence to: Mrs. Maja Lisik-Habib, Department of Chemotherapy, Medical University of Lodz, Copernicus Memorial Hospital, ul. Pabianicka 62, Lodz 93-513, Poland

E-mail: m.habib@interia.pl

Key words: Hodgkin's lymphoma, secondary cancer, breast cancer, gastrointestinal cancer, cancer survivorship

\section{Case report}

Hodgkin's lymphoma. In June 1985, a 43-year-old, previously healthy female presented at the Regional Oncological Center of Copernicus Memorial Hospital (Lodz, Poland) with a two-week history of a painless enlargement of the left supraclavicular lymph nodes. No fever, pruritus, night sweats or weight loss were noted. Physical examination revealed hard, immovable, $\sim 4 \mathrm{~cm}$ in diameter lymph nodes in the left supraclavicular area. Furthermore, bilateral hilar enlargement was identified upon chest X-ray. An excisional biopsy of the enlarged lymph node was performed and a diagnosis of HL (type, nodular sclerosis) was established. Additionally, a bone marrow biopsy and exploratory laparotomy were performed. The disease was staged at IIA according to the Ann Arbor staging system (3) and, in accordance with the standard of treatment at the present time, the patient underwent a splenectomy and received three cycles of MOPP/ABVE regimen chemotherapy (nitrogen mustard, $6 \mathrm{mg} / \mathrm{m}^{2}$ on day 1; vincristine, $2 \mathrm{mg}$ on day 1; procarbazin, $100 \mathrm{mg} / \mathrm{m}^{2}$ on days $1-7$; doxorubicin, $35 \mathrm{mg} / \mathrm{m}^{2}$ on day 8 ; bleomycin, $10 \mathrm{mg} / \mathrm{m}^{2}$ on day 8; vinblastine, $6 \mathrm{mg} / \mathrm{m}^{2}$ on day 8; prednisolone, $40 \mathrm{mg} / \mathrm{m}^{2}$ on days 1-14). After completion of the chemotherapy regimen, the patient was irradiated in the supradiaphragmatic and paraaortic lymph node areas, and achieved complete remission.

Secondary breast cancer. In June 2009, a screening mammography revealed an irregular high-density mass (size, 45x50 mm) with clusters of microcalcifications and a Breast Imaging, Reporting and Data System (4) score of 5 in the upper outer quadrant of the right breast. A fine needle aspiration biopsy was performed and breast cancer was confirmed (i.e., cancer cells were detected). In July 2009, the patient underwent a radical right mastectomy with axillary lymphadenectomy. Subsequent histopathological examination determined an invasive, grade two, estrogen and progesterone receptor (ER and PR)-positive (score 3+), HER2-negative ductal carcinoma lesion of the breast (diameter, $2.5 \mathrm{~cm}$ ) and metastasis to one of the axillary lymph nodes. Consequently, the patient received adjuvant treatment with tamoxifen (dose, $20 \mathrm{mg} /$ day) and remained in remission.

Secondary colon cancer. In April 2010 the patient began to complain of pain in the lower abdomen and persistent 
constipation. No obvious abnormalities were observed upon physical examination, however, morphological analysis revealed microcytic anemia: Red blood cells, $3.2 \mathrm{M} / \mu 1$ (normal range, 3.50-5.0 M/ $\mu \mathrm{l}$ ); hemoglobin, $10.2 \mathrm{~g} / \mathrm{dl}$ (normal range, $11.2-15.0 \mathrm{~g} / \mathrm{dl}$ ); mean cell volume, $76.3 \mathrm{fl}$ (normal range, $81-98 \mathrm{fl}$ ) and a high platelet count of $549 \mathrm{~K} / \mu \mathrm{l}$ (normal range, $150-400 \mathrm{~K} / \mu \mathrm{l})$. The patient was referred for a colonoscopy, which identified a mass in the left colic flexure. A pathology report of the biopsied mass indicated adenocarcinoma, and chest and abdomen computed tomography (CT) scans revealed no distant metastasis. The patient subsequently underwent a left hemicolectomy. The pathology report determined moderately differentiated pT3 adenocarcinoma, according to TNM staging system (5), and 5/20 pericolic lymph nodes were positive for stage IIIB metastatic carcinoma. A standard FOLFOX-4 adjuvant chemotherapy commenced, however, oxaliplatin was discontinued after nine cycles due to grade two neurotoxicity. Adjuvant chemotherapy was completely terminated in December 2010 after 12 courses.

One year later, the patient presented with a persistent dry cough of one month. An antibiotic treatment was administered due to the suspicion of a protracted infection of the lower respiratory tract, however, no improvement was observed. A chest X-ray identified non-specific densities at the right infraclavicular area and a chest CT scan confirmed the presence of two metastatic lesions in the second segment of the right lung (13 and $5 \mathrm{~mm}$ in diameter). The patient underwent a videothoracoscopy with a radical wedge resection. The pathology report indicated grade two metastatic tubular adenocarcinoma, which possibly corresponded to colorectal cancer metastasis; however, a positron emission tomography-CT scan did not reveal any other metastatic lesions. Following surgery the patient received no systemic treatment and remains under surveillance.

\section{Discussion}

Secondary malignancies are serious adverse effects of systemic therapy. According to the Surveillance, Epidemiology and End Results Program, secondary malignancies account for $16 \%$ of all cancer (6). Initially, the increased occurrence of secondary malignancies was reported in HL and multiple myeloma survivors $(7,8)$. Subsequent malignancies are now the leading cause of mortality in HL survivors (9). Various studies have assessed or quantified the risk of developing secondary cancers following the successful treatment of HL (9-20), however these studies have not produced consistent results, possibly due to differences in the number of patients included in the analyses, the characteristics of the study population, the length of the follow-up period, the chemotherapy schedule, the age of HL diagnosis, and the dose and volume of irradiation. Prior radiotherapy is considered to be a major risk factor in the development of secondary malignancies. As a combined modality treatment of radiotherapy and chemotherapy was frequently used in previous decades, less is known about effects of chemotherapy alone (10). Breast cancer is the most frequent solid tumor and the leading cause of mortality among female HL survivors (11-15); this increased risk of breast cancer persists $>30$ years after the primary treatment of HL $(21,22)$.
The incidence of secondary breast cancer depends on the dose and volume of irradiation, chemotherapy regimen used and the age at the time of treatment. The greatest risk of developing secondary breast cancer is reported in females who are $<30$ years old during HL treatment and in females administered with a treatment strategy of radiotherapy alone. The cumulative lifetime incidence in these females is almost $30 \%$ (23). Mantle field irradiation results in $>2$-fold increase in the risk of developing secondary breast cancer compared with the administration of a similar dose (36-44 Gy) of radiation restricted to the mediastinum (24). However, premature menopause and shorter exposure to endogenous estrogens caused by antineoplastic therapy appear to be protective factors (24-26). Furthermore, gonadotoxic treatment, which includes alkylating-based regimens and pelvic irradiation (dose, >5 Gy), results in a lower incidence of breast cancer $(16,18)$. However, in a recent meta-analysis, Ibrahim et al (22) assessed the risk of HL survivors developing secondary breast cancer and could not demonstrate a protective effect of gonadotoxic alkylating chemotherapy against this development. Despite this, Ibrahim et al did demonstrate that the use of chemotherapy as the sole therapeutic modality was not associated with a significantly greater relative risk (RR) of developing breast cancer [RR, 1.19; 95\% confidence interval (CI), 0.50-2.82].

Breast cancer in HL survivors with a history of radiation occurs at younger age compared with the general population. The breast cancer is typically bilateral and appears to be independent to other risk factors, such as obesity, smoking or the use of oral contraceptives (27-28). Secondary cancers are more often ER- and PR-negative when compared with primary tumors $(27,29,30)$. Less is known regarding the development of other solid tumors in HL survivors, although there is an increased cumulative risk of developing solid cancers other than breast cancer compared with the general population. The most common sites of secondary and primary cancer development are similar (9,31-35). Hodgson et al (9) identified that males and females diagnosed with HL at the age of 30 years have an 18 and 26\% thirty-year cumulative risk of developing secondary malignancies, respectively. Hodgson et al described 850 secondary cancers among 1,490 patients HL survivors and identified the colorectum as one of the predominant sites of the excess cancers (7\% of all excess cancers). Furthermore, the HL survivors exhibited a similar absolute risk of colorectal cancer at 35-40 years compared with the general population at the age of 50-54 years old. Youn et al (34) assessed long-term survival among HL survivors who developed secondary gastrointestinal cancers and demonstrated that overall survival was significantly reduced in comparison to primary cancer patients. Although radiotherapy is the predominant risk factor for development of secondary cancers, the risk is also increased following chemotherapy alone. In a British study, Swerdlow et al (35) reported the RR of secondary cancers as $3.9(95 \% \mathrm{CI}, 3.5-4.4)$ after combined modality treatment and 2.0 (95\% CI, 3.5-4.4) after chemotherapy alone. The risk of secondary cancers remained increased for $>25$ years after treatment. Furthermore, Swerdlow et al demonstrated that the 20-year cumulative risk of developing secondary cancers is $13 \%$ for patients treated with chemotherapy alone and $18 \%$ for patients who underwent combined modality treatment. Secondary malignancies were observed in 459/5,798 
HL survivors, of which 27 (5.8\%) were colorectal cancer. Combined-modality treated patients exhibited a significantly increased risk of developing colorectal cancer (RR, 2.0; 95\% CI, 1.2-3.2; $\mathrm{P}<0.05)$ in comparison with chemotherapy alone, which was not associated with significant risk (RR, 1.1; 95\% CI, 0.5-1.9). However, chemotherapy alone significantly increased the risk of developing lung cancer, leukemia and non-HL (35).

In conclusion, it is necessary to assess the potential risks and long-term complications of anticancer therapy among cancer survivors. Future efforts should be focused on developing novel screening strategies for individuals who have survived cancer, educating patients and introducing effective prevention strategies. Secondary malignancies appear at a younger age in cancer survivors compared with the general population, however, younger individuals are not recommended for routine screening. Thus, patients should be informed of the likelihood of developing secondary malignancies and preventative strategies among cancer survivors should be promoted.

\section{Acknowledgements}

The present study was supported by a grant from the Chemotherapy Clinic of the Medical University of Lodz (Lodz, Poland; grant no. 503/1-034-02/503-01).

\section{References}

1. Canellos GP, Rosenberg SA, Friedberg JW, Lister TA and Devita VT: Treatment of Hodgkin lymphoma: a 50-year perspective. J Clin Oncol 32: 163-168, 2014.

2. Brenner H, Gondos A and Pulte D: Ongoing improvement in long-term survival of patients with Hodgkin disease at all ages and recent catch-up of older patients. Blood 111: 2977-1983, 2008

3. Carbone PP, Kaplan HS, Musshoff K, et al: Report of the Committee on Hodgkin's Disease Staging Classification. Cancer Res 31: 1860-1861, 1971.

4. Eberl MM, Fox CH, Edge SB, et al: BI-RADS classification for management of abnormal mammograms. J Am Board Fam Med 19: 161-164, 2006.

5. Sobin LH, Gospodarowicz MK and Wittekind C (eds): Colon and rectum. In: TNM Classification of Malignant Tumours. 7th edition. Wiley-Blackwell, pp100-106, 2009.

6. Reis LAG, Melbert D, Krapcho M, et al; National Cancer Institute: SEER cancer statistics review, 1975-2004. http://seer.cancer.gov/csr/1975_2004/. Accessed April 8, 2014.

7. Arseneau JC, Sponzo RW, Levin DL, et al: Nonlymphomatous malignant tumors complicating Hodgkin's disease. Possible association with intensive therapy. N Engl J Med 287: 1119-1112, 1972.

8. Canellos GP, Arseneau JC, DeVita VT, Whang-Peng J and Johnson RE: Second malignancies complicating Hodgkin's disease in remission. Lancet 1: 947-949, 1975.

9. Hodgson DC, Gilbert ES, Dores GM, et al: Long-term solid cancer risk among 5-year survivors of Hodgkin's lymphoma. J Clin Oncol 25: 1489-97, 2007.

10. Franklin J, Pluetschow A, Paus M, et al: Second malignancy risk associated with treatment of Hodgkin's lymphoma: meta-analysis of the randomised trials. Ann Oncol 17: 1749-1760, 2006

11. Henry-Amar M and Somers R: Survival outcome after Hodgkin's disease: a report from the international data base on Hodgkin's disease. Semin Oncol 17: 758-768, 1990.

12. Cosset JM, Henry-Amar M and Meerwaldt JH: Long-term toxicity of early stages of Hodgkin's disease therapy: the EORTC experience. EORTC Lymphoma Cooperative Group. Ann Oncol 2 (Suppl 2): 77-82,1991.

13. Mauch PM, Kalish LA, Marcus KC, et al: Long-term survival in Hodgkin's disease relative impact of mortality, second tumors, infection, and cardiovascular disease. Cancer J Sci Am 1: 33-42, 1995.
14. Hoppe RT: Hodgkin's disease: complications of therapy and excess mortality. Ann Oncol 8: 115-118, 1997.

15. Aleman BM, van den Belt-Dusebout AW, Klokman WJ, Bartelink H, Van't Veer MB and van Leeuwen FE: Long-term cause-specific mortality of patients treated for Hodgkin's disease J Clin Oncol 21: 3431-3439, 2003.

16. Henry-Amar M: Second cancer after the treatment for Hodgkin's disease: a report from the International Database on Hodgkin's Disease. Ann Oncol 3 (Suppl 4): 117-128, 1992.

17. Swerdlow AJ, Douglas AJ, Vaughan Hudson G, et al: Risk of second primary cancers after Hodgkin's disease by type of treatment: analysis of 2,846 patients in the British National Lymphoma Investigation. Brit Med J 304: 1137-1143, 1992.

18. Abrahamsen JF, Andersen A, Hannisdal E, et al: Second malignancies after treatment of Hodgkin's disease: the influence of treatment, follow-up time, and age. J Clin Oncol 11: 255-261, 1993.

19. van Leeuwen FE, Klokman WJ, Hagenbeek A, et al: Second cancer risk following Hodgkin's disease: a 20 -year follow-up study. J Clin Oncol 12: 312-325, 1994.

20. Dores GM, Metayer C, Curtis RE, et al: Second malignant neoplasms among long-term survivors of Hodgkin's disease: a population-based evaluation over 25 years. J Clin Oncol 20: 3484-3494, 2002.

21. Hancock SL, Tucker MA and Hoppe RT: Breast cancer after treatment of Hodgkin's disease. J Natl Cancer Inst 85: 25-31, 1993.

22. Ibrahim EM, Abouelkhair KM, Kazkaz GA, Elmasri OA and Al-Foheidi M: Risk of second breast cancer in female Hodgkin's lymphoma survivors: a meta-analysis. BMC Cancer 12: 197, 2012.

23. Crump M and Hodgson D: Secondary breast cancer in Hodgkin's lymphoma survivors. J Clin Oncol 27: 4229-4231, 2009.

24. De Bruin ML, Sparidans J, Van't Veer MB, et al: Breast cancer risk in female survivors of Hodgkin's lymphoma: Lower risk after smaller radiation volumes. J Clin Oncol 27: 4239-4246, 2009.

25. Cooke R, Jones ME, Cunningham D, et al; England and Wales Hodgkin Lymphoma Follow-up Group: Breast cancer risk following Hodgkin lymphoma radiotherapy in relation to menstrual and reproductive factors. Br J Cancer 108: 2399-2406, 2013.

26. Travis LB, Curtis RE and Boice JD Jr: Late effects of treatment for childhood Hodgkin's disease. N Engl J Med 335: 352-353, 1996.

27. Milano MT, Li H, Gail MH, et al: Long-term survival among patients with Hodgkin's lymphoma who developed breast cancer: a population-based study. J Clin Oncol 28: 5088-5096, 2010.

28. Elkin EB, Klem ML, Gonzales AM, et al: Characteristics and outcomes of breast cancer in women with and without a history of radiation for Hodgkin's lymphoma: a multi-institutional, matched cohort study. J Clin Oncol 29: 2466-2473, 2011.

29. Dores GM, Anderson WF, Beane Freeman LE, Fraumeni JF Jr, and Curtis RE: Risk of breast cancer according to clinicopathologic features among long-term survivors of Hodgkin's lymphoma treated with radiotherapy. Br J Cancer 103: 1081-1084, 2010.

30. Veit-Rubin N, Rapiti E, Usel M, et al: Risk, characteristics, and prognosis of breast cancer after Hodgkin's lymphoma. Oncologist 17: 783-791, 2012.

31. Ng AK, Bernardo MV, Weller E, et al: Second malignancy after Hodgkin disease treated with radiation therapy with or without chemotherapy: long-term risks and risk factors. Blood 100: 1989-1996, 2002.

32. Ibrahim EM, Kazkaz GA, Abouelkhair KM, Al-Mansour MM, et al: Increased risk of second lung cancer in Hodgkin's lymphoma survivors: a meta-analysis. Lung 191: 117-134, 2013.

33. Xu Y, Wang H, Zhou S, et al: Risk of second malignant neoplasms after cyclophosphamide-based chemotherapy with or without radiotherapy for non-Hodgkin lymphoma. Leuk Lymphoma 54: 1396-1404, 2013.

34. Youn P, Li H, Milano MT, Stovall M, Constine LS and Travis LB: Long-term survival among Hodgkin's lymphoma patients with gastrointestinal cancer: a population-based study. Ann Onocol 24: 202-208, 2013.

35. Swerdlow AJ, Higgins CD, Smith P, et al: Second cancer risk after chemotherapy for Hodgkin's lymphoma: a collaborative British cohort study. J Clin Oncol 29: 4096-4104, 2011. 